\title{
ZIC1 acts a tumor suppressor in breast cancer by targeting survivin
}

\author{
WEI HAN $^{1 *}$, FANG CAO $^{1 *}$, XIAO-JIAO GAO ${ }^{2}$, HUA-BING WANG $^{3}$, FANG CHEN $^{2}$, SI-JIAN CAI $^{4}$, \\ $\mathrm{CONG}_{\mathrm{ZHANG}}{ }^{5}$, YONG-WEI HU ${ }^{1}$, JUN MA ${ }^{6}, \mathrm{XING} \mathrm{GU}^{7}$ and HOU-ZHONG DING ${ }^{1}$

\begin{abstract}
Departments of ${ }^{1}$ General Surgery and ${ }^{2}$ Pathology, Kunshan First People's Hospital Affiliated to Jiangsu University, Kunshan, Jiangsu 215300; ${ }^{3}$ Department of General Surgery, Luan First People's Hospital, Luan, Anhui 237000, P.R. China;

${ }^{4}$ Business School, York St. John University, York YO31 7EX, UK; Departments of ${ }^{5}$ Pharmacy and ${ }^{6}$ Urinary Surgery,

Kunshan Hospital of Traditional Chinese Medicine, Kunshan, Jiangsu 215300; 7 Department of Gynecology,

Kunshan First People's Hospital Affiliated to Jiangsu University, Kunshan, Jiangsu 215300, P.R. China
\end{abstract}

Received February 23, 2018; Accepted June 1, 2018

DOI: $10.3892 /$ ijo.2018.4450

\begin{abstract}
In this study, we aimed to identify the tumor suppressive roles of zinc finger of the cerebellum 1 (ZIC1) in patients with malignant breast neoplasms and to examine the association between $\mathrm{ZIC1}$ and survivin expression. For this purpose, 140 invasive breast cancer specimens, 1,075 RNA breast cancer samples from The Cancer Genome Atlas (TCGA), 6 human breast cancer cell lines and MCF-10A normal breast epithelial cells were selected in order to compare the expression level of ZIC1 with that of survivin via immunohistochemistry and western blot analysis. Subsequently, the MDA-MB-231 and SK-BR3 cells with a lower ZIC1 expression were transfected with rLV-Zic1-PGK-Puro lentivirus or rLV-ZsGreen-PGK-Puro lentivirus in order to observe any alterations in cell proliferation and apoptosis through MTT assay, colony formation assay, mitochondrial membrane potential assay and flow cytometric analysis, and to analyze the modulation of molecular mechanisms by western blot analysis. In addition, xenograft mouse models were constructed to explore the role of $\mathrm{ZIC} 1$ in the growth of implanted tumors. The results revealed that ZIC1 negatively correlated with survivin in tumors and cells, and a higher ZIC1 RNA expression indicated a better overall survival in the 1,075 TCGA RNA breast cancer samples. In vitro, the overexpression of ZIC1 inhibited cell proliferation, reduced mitochondrial membrane potential and promoted the apoptosis of the MDA-MB-231 and SK-BR3 breast cancer cells by inactivating the Akt/mTOR/P70S6K pathway, suppressing survivin expression, modulating the cell cycle, releasing
\end{abstract}

Correspondence to: Dr Hou-Zhong Ding, Department of General Surgery, Kunshan First People's Hospital Affiliated to Jiangsu University, 5 Qingyang Mid Road, Kunshan, Jiangsu 215300, P.R. China E-mail: dinghouzhong@163.com

*Contributed equally

Key words: zinc finger of the cerebellum 1, survivin, breast cancer cytochrome $c$ (Cyto-c) into the cytosol and activating caspase proteins. In vivo, an elevated ZIC1 expression suppressed the growth of implanted tumors and downregulated survivin expression in tumors. On the whole, the findings of this study demonstrate that $\mathrm{ZIC1}$ plays a tumor suppressive role in breast cancer, by targeting surviving, significantly downregulating its expression.

\section{Introduction}

Breast cancer, one of the most common malignancies affecting women, has attracted increasing attention by the international community and has evoked tremendous interest paritcularly in the medical and academic fields (1). An increasing number of studies have been performed to explore potential biomarkers which may be involved in the initiation and progression of breast cancer. Estrogen receptor (ER), progesterone receptor (PR), c-erbB-2, p53 and Ki-67 have been investigated in the conventional histopathological setting $(2,3)$. However, numerous other genes and proteins are also involved in the abnormal regulation of signaling pathways and the progression of beast cancer.

Zinc finger of the cerebellum 1 (ZIC1) is located on chromosome $3 \mathrm{q} 25.1$ and belongs to the ZIC family. ZIC1 encodes a zinc finger transcription factor and is involved in the mediation of growth and physiological metabolism $(4,5)$. Studies have reported that ZIC1 is a putative suppressor gene in various carcinomas, including digestive system cancers and thyroid cancer (6-8). Moreover, its stimulation inhibits the growth of cancer cells by reducing Akt and Erk phosphorylation (6-8). The methylation frequency of ZIC1 in a variety of tumors has been shown to be significantly higher than that in the corresponding non-cancerous tissues (7-9). In addition, a high expression of ZIC1 has become a potential biomarker for a good prognosis (10). In breast cancer, the expression of ZIC1 has been shown to be elevated in BT-549 cells following the knockdown PIGX, RCN1, or RCN2, along with the growth of transfected cells being markedly inhibited (11). However, a further mechanistic analysis of ZIC1 in breast cancer still needs to be conducted. 
Survivin, known as baculoviral IAP repeat containing 5 (BIRC5), is located on chromosome 17q25.3. As an inhibitor of apoptotic proteins, survivin plays an important role in controlling cell mitosis, and enhancing the resistance to anticancer agents $(12,13)$. Moreover, it is frequently overexpressed in multifarious tumors, including breast cancer, while it is rarely expressed in normal human tissues (12-15). These findings suggest that elevated survivin is involved in carcinogenesis. In addition, previous studies have demonstrated that survivin suppresses the apoptosis of cancer cells through the inactivation of caspase- 9 and caspase-3 $(16,17)$. In addition, the phosphorylation of Akt and mammalian target of rapamycin (mTOR) is considered to be responsible for the upregulation of surviving $(16,17)$. Therefore, this study was designed to identify the role of ZIC1 in breast cancer in vitro and in vivo, and to examine the association of ZIC1 with surviving, elucidating the underlying molecular mechanisms.

\section{Materials and methods}

Patients and tissue specimens. Specimens from a total of 120 patients with invasive breast cancer who underwent radical mastectomy at Shanghai Changhai Hospital (Shanghai, China) from January, 2014 to December, 2015 were collected, with a mean age of $52.19 \pm 12.38$ years. Each case consisted of a breast tumor and its corresponding adjacent normal tissue. None of the patients had received radiotherapy or chemotherapy prior to surgery. In addition, 20 pairs of fresh-frozen invasive breast tumors and matched normal tissues were also collected from Kunshan First People's Hospital Affiliated to Jiangsu University (Kunshan, China) and were used for total protein extraction and western blot analysis, following the approval of Kunshan First People's Hospital Ethics Committee. Each patient signed the informed consent form.

A database (https://www.proteinatlas.org/), the Human Protein Atlas (HPA), which is a Swedish-based program, containing 1,075 TCGA RNA breast cancer samples with overall survival information and human genome-wide expression analyses, was also used. We selected this database to compare the RNA level of ZICl with that of survivin and to explore the prognostic roles of ZIC1 and survivin in patients with breast cancer. More detailed information of these two genes can be found in the following websites: For ZIC1, https://www.proteinatlas. org/ENSG00000152977-ZIC1/pathology/tissue/breast+cancer;and for survivin, https://www.proteinatlas.org/ENSG00000089685BIRC5/pathology/tissue/breast+cancer.

Cell lines and cell culture. Human breast cancer cell lines (MCF-7, MDA-MB-231, MDA-MB-453, SK-BR3, BT-474 and BT-549) and the human mammary epithelial cell line, MCF-10A, were obtained from the Cell Center at the Institutes of Biomedical Sciences (IBS), Fudan University, Fudan, China. All cancer cell lines were cultured in appropriate medium supplemented with $10 \%$ fetal bovine serum (FBS; Gibco Life Technologies/Thermo Fisher Scientific, Waltham, MA, USA) and $1 \%$ antibiotic/antimycotic solution (Sigma-Aldrich, St. Louis, MO, USA) at $37^{\circ} \mathrm{C}$ in a humidified atmosphere containing $5 \% \mathrm{CO}_{2}$ with Dulbecco's modified Eagle's medium (DMEM) for the MCF-7 and SK-BR3 cells; RPMI-1640 for the MDA-MB-231, BT-549 and BT-474 cells; and Leibovitz's L-15 (all from Gibco Life Technologies/Thermo Fisher Scientific) for the MDA-MB-453 cells. The MCF-10A cells were grown in specific medium with DF-12 $+5 \%$ HS + EGF $(20 \mathrm{ng} / \mathrm{ml})+$ hydrocortisone $(0.5 \mu \mathrm{g} / \mathrm{ml})+$ choleratoxin $(100 \mu \mathrm{g} / \mathrm{ml})+$ insulin $(10 \mu \mathrm{g} / \mathrm{ml})$.

Cell transfection. The MDA-MB-231 and SK-BR3 cells were cultured for $24 \mathrm{~h}$ in a 24-well plate and transfected with rLV-Zic1-PGK-Puro lentivirus and rLV-ZsGreen-PGK-Puro lentivirus (Wuhan Biobuffer Biotechnology Service Co., Ltd., Wuhan, China) when the cells reached a confluence of $30-60 \%$. The medium for the transfected cells was supplemented with polybrene $(8 \mathrm{mg} / \mathrm{ml}$; Sigma-Aldrich) to elevate the transfection efficiency. After $24 \mathrm{~h}$, the transfected cells were selected in a new cell culture medium with $0.5-1.0 \mu \mathrm{g} / \mathrm{ml}$ puromycin (TargetMol, Shanghai, China) for 10-12 days. The cells transfected with rLV-ZsGreen-PGK-Puro were classified as the 'Vector' group and the cells transfected with rLV-Zic1-PGKPuro were classified as the 'ZICl' group. Green fluorescent protein (GFP) in the 'Vector' group was observed using a fluorescence microscope (IX73; Olympus, Shanghai, China) to examine the efficiency of transfection. In addition, when we constructed the lentiviral expression vector of the $\mathrm{ZIC} 1$ gene, the locus of GFP expression was cut off. As a result, the cells transfected with rLV-Zic1-PGK-Puro failed to produce GFP, and only the cells transfected with rLV-ZsGreen-PGK-Puro were observed through a fluorescence microscope. To resolve this issue, we also performed western blot analysis and examined the efficiency of transfection in the 'ZICl' and 'Vector' groups. The time period between transfection and subsequent experimentation was $<4$ weeks.

Reverse transcription-quantitative PCR (RT-qPCR). The transfected cells were collected to isolate total RNA using TRIzol regent (Thermo Fisher Scientific). A total of $2 \mu \mathrm{g}$ RNA of each sample was reverse transcribed using the SuperScript II RNaseReverse Transcriptase system (Thermo Fisher Scientific). cDNA was subjected to qPCR using primers specific for ZIC1, survivin and GAPDH. The PCR primers were designed as follows: ZIC1 forward, 5'-GCGTCCTTTTGTGGATCTTTAA-3' and reverse, 5'-AGTAATCACATCTGCTTCTGGG-3' (178 bp); survivin forward, 5'-ATGTCCATTTTTCAGGTTCTCTAAG-3' and reverse, 5'-GCACTGCTGTCTCTACTTTCC-3' (142 bp); and GAPDH (internal control) forward, 5'-GAAGGTGAAGG TCGGAGT-3' and reverse, 5'-GAAGATGGTGATGGGAT TTC-3' (226 bp). The PCR cycling conditions were as follows: i) $94^{\circ} \mathrm{C}$ for $4 \mathrm{~min}$; ii) 40 cycles of $95^{\circ} \mathrm{C}$ for $1 \mathrm{~min}$; iii) $60^{\circ} \mathrm{C}$ for $1 \mathrm{~min}$; and iv) $72^{\circ} \mathrm{C}$ for $1 \mathrm{~min}$. Amplified DNA was measured using the SYBR Premix Ex Taq ${ }^{\mathrm{TM}}$ kit (Takara Bio, Tokyo, Japan), and qPCR was performed using an iQ5 real-time PCR detection system (Bio-Rad, Hercules, CA, USA). We then used the $2^{-\Delta \Delta \mathrm{Cq}}$ value to calculate the relative expression and $\Delta \Delta \mathrm{Cq}=\left(\mathrm{Cq}^{\text {rLV-Zicl-PGK-Puro-ZICl/survivin }}-\mathrm{Cq}^{\text {rLVV-Zicl-PGK-Puro-GAPDH }}\right)-$ $\left(\mathrm{Cq}^{\text {Vector-ZIC1/survivin-CqVector-GAPDH}}\right)$ (18).

Cell viability assay. To assess cell proliferation, the stably transfected cells seeded in 96-well plates for 1-5 days, were treated with MTT (Sigma-Aldrich), 3-(4,5-Dimethylthigal-2-yl)-2,5(diphenyltetragalium) bromide for $4 \mathrm{~h}$ at the incubator. The 
supernatant was replaced with DMSO, and then the 96-well plates were oscillated for $10 \mathrm{~min}$. The absorbance of each group was read at $490 \mathrm{~nm}$ of the microplate reader (OD value) (MD/F5; Shanghai Magvalley Technology Co., Ltd., Shanghai, China).

Colony formation assay. Stably transfected cells were seeded in 6-well plates at a density of 200 cells and cultured for about 10 days, when the clones were visible ( $\geq 50$ cells). The colonies were fixed for 15 min with methanol, and stained with crystal violet for $15 \mathrm{~min}$ after airing. Then, the numbers of colonies were counted.

Cell cycle analysis. Stably transfected cells were treated with $0.25 \%$ trypsin without EDTA (Gibco Life Technologies/Thermo Fisher Scientific) at $37^{\circ} \mathrm{C}$ for approximately 5 min. Subsequently, after being neutralized by medium, the cells were centrifuged at $1,000 \mathrm{x}$ g for $5 \mathrm{~min}$. The centrifuged cells were washed 2 times with pre-cooling phosphate-buffered saline (PBS), and were fixed in $80 \%$ ethanol for $12 \mathrm{~h}$ at $4^{\circ} \mathrm{C}$. The cells were then washed twice again with pre-cooling PBS prior to incubation for $30 \mathrm{~min}$ at $37^{\circ} \mathrm{C}$ in the dark with propidium iodide (PI) and RNAse A (KeyGen Biotech, Nanjing, China). Fluorescence-activated cell sorting analysis was performed using a flow cytometer (FACScalibur, E97600114; BD Biosciences, New Jersey, NY, USA).

Analysis of cell apoptosis. Due to the expression of GFP in the 'Vector' group only, we selected red the fluorescent proteins, Annexin V-APC and 7-AAD as the fluorescent markers in cell apoptosis assay. Stably transfected cells were treated with $0.25 \%$ trypsin without EDTA (Gibco Life Technologies/Thermo Fisher Scientific) at $37^{\circ} \mathrm{C}$ for approximately $5 \mathrm{~min}$. Subsequently, after being neutralized by medium, the cells were centrifuged at $1,000 \mathrm{x}$ for $5 \mathrm{~min}$. The centrifuged cells were washed 2 times with PBS, and stained with Annexin V-APC and 7-AAD for $15 \mathrm{~min}$ at room temperature in the dark (KeyGen Biotech). After being diluted in moderate PBS, the stained cells were analyzed using a flow cytometer.

Western blot analysis. Proteins from tissues or cells were extracted using RIPA extraction buffer with PMSF (Beyotime Institute of Biotechnology, Shanghai, China) and phosphatase inhibitor (CWBio, Beijing, China). BCA was used for protein quantification and the proteins were then processed for western blot analysis by means of $8-16 \%$ pre-cast protein gel electrophoresis (Thermo Fisher Scientific) at $20 \mu \mathrm{g}$ per lane and were transferred onto PVDF membranes (Beyotime Institute of Biotechnology). ZIC1 (1:500; bs-11609R; Bioss Biotechnology, Beijing, China), survivin (RLM3419), Akt (RLT0178), p-Akt (RLP0006), mTOR (RLT2915), p-mTOR (RLP0176), cleaved caspase-9 (RLC0012), cleaved caspase-3 (RLC0004) (all 1:1,000; Suzhou Ruying Biotechnology, Suzhou, China), cyclin D1 (bs-20596R, 1:1,000; Bioss Biotechnology), p21 (YT3497), p27 (YT3501) (both 1:500; ImmunoWay Biotechnology, Piano, TX, USA), P70S6K (2708S), p-P70S6K (9204S), Bcl-2 (15071S), Bad (9268S), p-Bad (9291S) and Bcl-xL (2764S) (all 1:1,000) were used as the primary antibodies, and GAPDH $(5174 \mathrm{~S}, 1: 1,000)$ (both from Cell Signaling Technology, Danvers, MA, USA) was used as the reference protein. The secondary antibodies were HRP-labeled goat anti-rabbit IgG (A0208) and HRP-labeled goat anti-mouse IgG (A0216) (both 1:1,000; Beyotime Institute of Biotechnology). The enhanced chemiluminescent (ECL) kit (Beyotime Institute of Biotechnology) was used to detect the results of western blot analysis. The relative level of each protein was deduced from the ratio of the mean value of each band to that of GAPDH. The relative densities were quantified with a digital imaging analyzer, ImageJ 1.4.1.

Mitochondrial membrane potential assay. In order to detect cytochrome $c$ (Cyto-c) expression in the mitochondria and cytoplasm, we first extracted mitochondrial cytosolic proteins sing the Minute ${ }^{\mathrm{TM}}$ Mitochondria Isolation kit (Invent Biotechnologies, Inc., Plymouth, MN, USA). Cyto-c (A13430, 1:1,000; ABclonal Technology, Wuhan, China) in the mitochondria or cytosol was detected by by western blot analysis as described above. In addition, COX-IV (A6564) and tubulin (A0482) (1:1,000; ABclonal Technology) were used as the reference proteins of the mitochondria and cytosol, respectively. The JC-1 kit (Beyotime Institute of Biotechnology) was used to investigate the level of red fluorescence and green fluorescence in mitochondrial proteins using a microplate reader (Shanghai Magvalley Technology Co., Ltd.). The ratio of red to green fluorescence was used to measure the level of depolarization of the mitochondria.

Construction of xenograft mouse models. A total of 6 female BALB/C-nu/nu nude mice (5-6 weeks old, mean weight upon purchase, $19.02 \pm 0.29 \mathrm{~g}$ ) were purchased from Wuhan Biobuffer Biotechnology Service Co., Ltd. (Wuhan, China). The aniamls were kept in an environment at $28^{\circ} \mathrm{C}$ and $50 \%$ humidity under pathogen-free conditions with access to aseptic food and water. We randomly divided the nude mice into 2 groups as follows: The 'Vector' group (rLV-ZsGreen-PGK-Puro) and the 'ZIC1' group (rLV-Zic1-PGK-Puro). Stably transfected MDA-MB-231 cells were collected in the logarithmic growth phase, and were suspended in serum-free medium at a concentration of $2.5 \times 10^{7}$ cells $/ \mathrm{ml}$. Subsequently, we injected $0.2 \mathrm{ml}$ subcutaneously into the right lateral back area of the BALB/C-nu/nu nude mice. The mice were observed for tumor growth from 5 to 39 days, and the tumor volume $\left(\mathrm{mm}^{3}\right)$ was measured as follows: Tumor volume $\left(\mathrm{mm}^{3}\right)=$ length $(\mathrm{mm}) \times$ width $^{2}\left(\mathrm{~mm}^{2}\right) / 2$. After 39 days, the nude mice were euthanized (mean weight upon sacrifice, $19.37 \pm 0.60 \mathrm{~g}$ ). The tumors were excised, cut into paraffin sections and used for immumohistochemical staining. All animal research was carried out following the approval of the Jiangsu University Animal Ethics Committee (Jiangsu, China).

Immunohistochemistry. Paraffin-embedded consecutive sections were subjected to immunohistochemical staining for the expression of $\mathrm{ZICl}$ and survivin, with the same primary antibodies as those used in western blot analysis, diluted at 1:100 in PBS, with a SP Rabbit \& Mouse HRP Kit (CWBio). PBS without primary antibodies was used as a negative control. Two pathologists independently evaluated the scores of ZIC1 and survivin expression through a semi-quantitative assessment system, with an immunoreactivity score (IRS), 
A
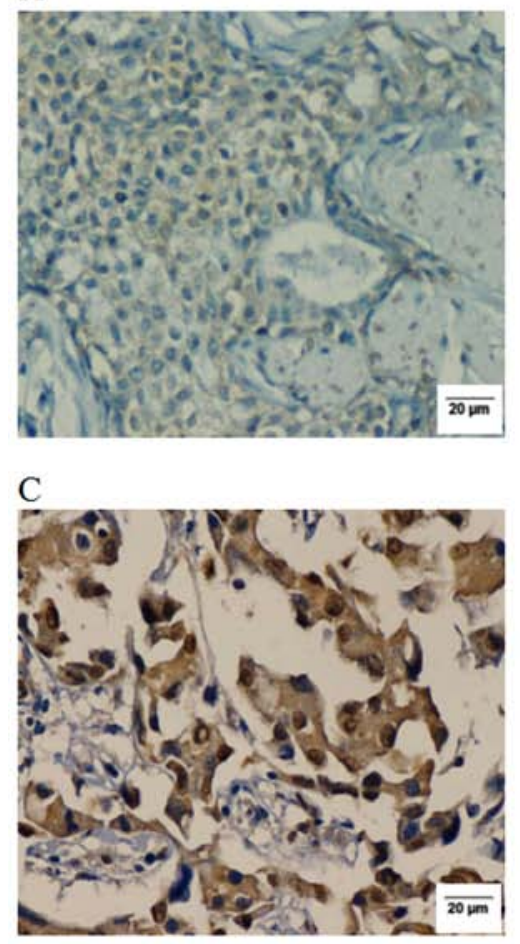

B

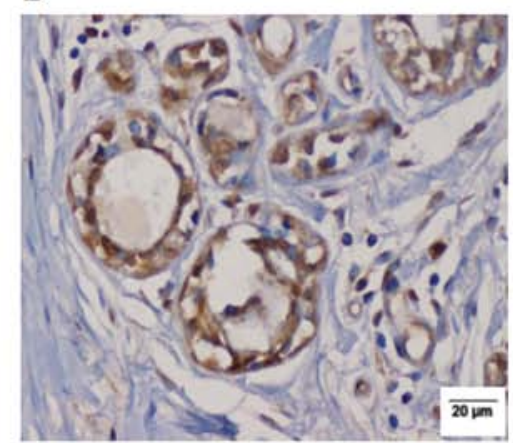

D

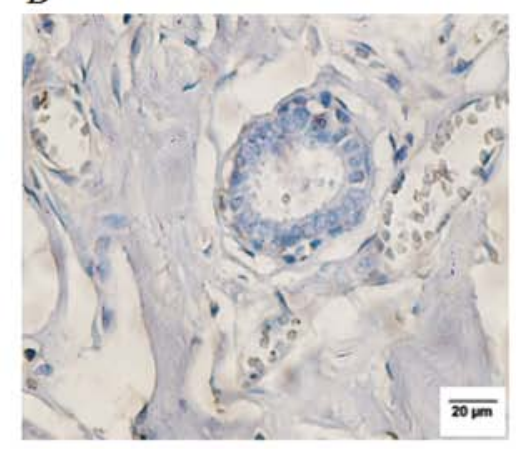

$\mathrm{E}$



F

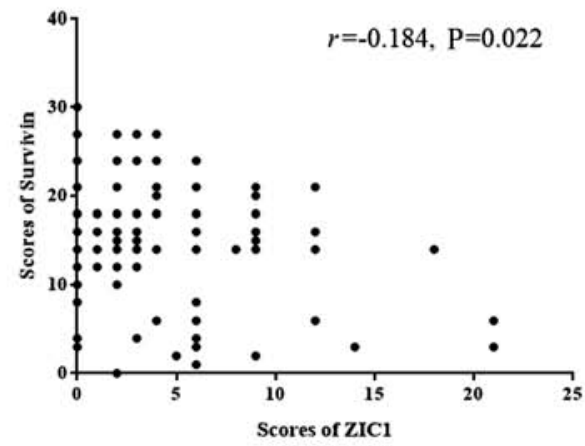

Figure 1. The expression of ZIC1 and survivin in 120 female invasive breast tumors was examined by immunohistochemistry (magnification, x400). (A) Expression of ZIC1 in breast carcinoma; (B) expression of ZIC1 in corresponding adjacent normal tissues; (C) expression of survivin in breast carcinoma; (D) expression of survivin in corresponding adjacent normal tissues; (E) IRS scores of ZIC1 and survivin expression in breast tumors and corresponding adjacent normal tissues ${ }^{* * *} \mathrm{P}<0.001$; (F) Correlation analysis of ZIC1 and survivin expression in breast tumors.

which was combined by a score of the percentage of cells ('0-100\%' = '0-10'), and a score of the staining intensity ( 0 , no staining of cells; 1 , mild staining; 2 , moderate staining; and 3 , marked staining). When different intensities were detected in the cytoplasm and nucleus, we used an average score of the cytoplasm and nucleus. The total score ranged from 0 to 30 , and any disagreement was resolved by discussion.

Statistical analysis. All results were analyzed using a t-test with SPSS 20.0 software, and a value of $\mathrm{P}<0.05$ was considered to indicate a statistically significant difference. The differences of protein/gene expression between the breast tumors and matched normal tissues or the differences between ZIC1 and survivin expression in tissues were analyzed with a paired t-test, and the differences in protein expression or biological behaviors between the 'Vector' group and 'ZIC1' group were analyzed by an unpaired t-test. An ANOVA followed by Tukey's multiple comparisons test was used to compare ZIC1/survivin expression levels in the 7 cell lines. Continuous variables are expressed as the means \pm SD and Spearman's correlation analysis was also performed to assess the correlation between ZIC1 expression and survivin in 120 cases. In addition, Pearson's Chi square test were used to analyze the associations of ZIC protein expression with the patient clinicopathological characteristics. Kaplan-Meier analysis and the log rank test were also conducted to analyze the overall survival of the 1,075 patients from HPA. All graphs were generated using GraphPad Prism 6.0 software, and all figures were generated using Adobe Photoshop CS5.

\section{Results}

ZIC1 expression inversely correlates with surviving expression in breast tumors. We investigated the expression of $\mathrm{ZIC1}$ and survivin in invasive breast cancer by immunohistochemistry and western blot analysis. As shown in Fig. 1A-D, ZIC1 was expressed mainly in the cytoplasm, while survivin were expressed both in the cytoplasm and nucleus. The mean score of $\mathrm{ZIC} 1$ in the tumors was $3.70 \pm 4.44$, and was significantly lower than that in normal tissues $(10.46 \pm 9.37, \mathrm{P}<0.001)$. The mean score of survivin in the tumors was markedly higher than that in normal tissues $(15.63 \pm 6.35$ vs. $4.08 \pm 3.20$, $\mathrm{P}<0.001)$. In addition, the mean score of ZIC1 in the tumors was also significantly lower than that of survivin in the tumors $(\mathrm{P}<0.001)$ (Fig. 1E). A negative correlation was also observed between the scores of $\mathrm{ZIC} 1$ and survivin $(\mathrm{P}=0.022$, Fig. $1 \mathrm{~F})$, which indicated that ZIC1 expression inversely correlated with survivin expression in the breast tumors. The results of western blot analysis of 20 pairs of fresh-frozen tissues also yielded a similar result (Fig. 2A and B).

Associations of ZIC1 and survivin expression with the patient clinicopathological characteristics. Subsequently, in order to evaluate the association between $\mathrm{ZIC1}$ /survivin and the patient clinicopathological characteristics, we respectively divided the 120 cases into 2 groups according to the cut-off value (the cut-off of ZIC1 was 4; and the cut-off of Survivin was 16; Table I). ZIC1 expression was negatively associated with tumor differentiation $(\mathrm{P}=0.040)$ and TNM staging $(\mathrm{P}=0.016)$, while survivin expression was positively associated 
Table I. Associations of ZIC1/survivin expression with various clinicopathological characteristics of the 120 patients with invasive breast cancer.

\begin{tabular}{|c|c|c|c|c|c|c|c|c|c|}
\hline \multirow[b]{2}{*}{ Parameters } & \multirow[b]{2}{*}{$\mathrm{n}$} & \multicolumn{2}{|c|}{ ZIC1 expression (cut-off=4) } & \multirow[b]{2}{*}{$\chi^{2}$ value } & \multirow[b]{2}{*}{ P-value } & \multicolumn{2}{|c|}{ Survivin expression (cut-off $=16$ ) } & \multirow[b]{2}{*}{$\chi^{2}$ value } & \multirow[b]{2}{*}{ P-value } \\
\hline & & $(n$, score $>4)$ & $(\mathrm{n}$, score $\leq 4)$ & & & $(\mathrm{n}$, score $>16)$ & $(\mathrm{n}$, score $\leq 16)$ & & \\
\hline Total & 120 & 36 & 84 & & & 50 & 70 & & \\
\hline \multicolumn{10}{|l|}{ Age, years } \\
\hline$\leq 50$ & 67 & 18 & 49 & 0.710 & NS & 31 & 36 & 1.322 & NS \\
\hline$>50$ & 53 & 18 & 35 & & & 19 & 34 & & \\
\hline \multicolumn{10}{|l|}{ Tumor size } \\
\hline$\leq 5 \mathrm{~cm}$ & 82 & 23 & 59 & 0.469 & NS & 36 & 46 & 0.533 & NS \\
\hline$>5 \mathrm{~cm}$ & 38 & 13 & 25 & & & 14 & 24 & & \\
\hline \multicolumn{10}{|c|}{ Tumor differentiation } \\
\hline Well & 40 & 18 & 22 & 6.452 & 0.040 & 11 & 29 & 17.167 & $<0.001$ \\
\hline Moderate & 52 & 12 & 40 & & & 18 & 34 & & \\
\hline Poor & 28 & 6 & 22 & & & 21 & 7 & & \\
\hline \multicolumn{10}{|c|}{ Lymph node metastasis } \\
\hline Positive & 79 & 20 & 59 & 2.415 & NS & 38 & 41 & 3.939 & 0.047 \\
\hline Negative & 41 & 16 & 25 & & & 12 & 29 & & \\
\hline \multicolumn{10}{|c|}{ TNM staging } \\
\hline I & 27 & 13 & 14 & 8.258 & 0.016 & 14 & 13 & 19.305 & $<0.001$ \\
\hline II & 54 & 17 & 37 & & & 11 & 43 & & \\
\hline III & 39 & 6 & 33 & & & 25 & 14 & & \\
\hline
\end{tabular}



B



C

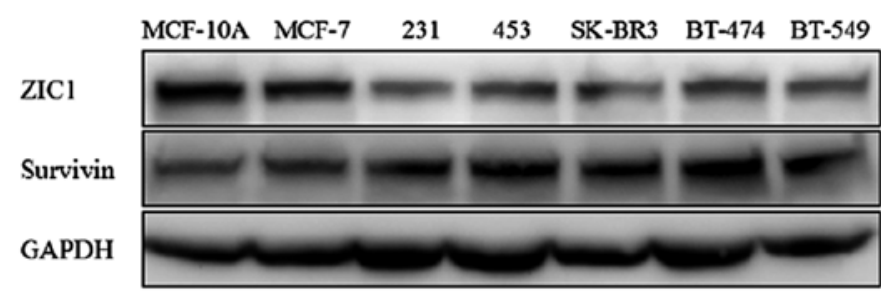

$\mathrm{D}$

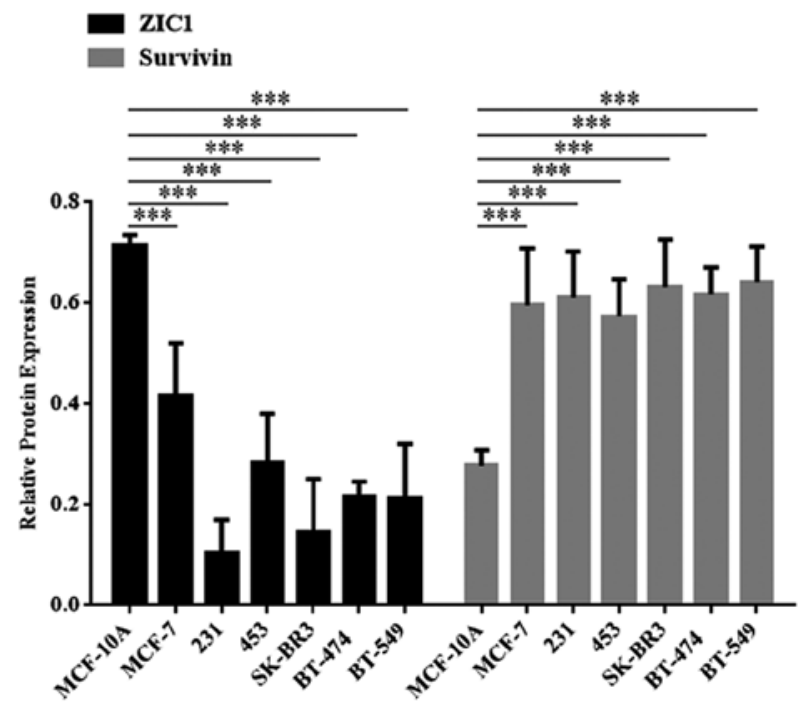

Figure 2. The expression of ZIC1 and survivin in 20 pairs of fresh-frozen invasive breast tumors and 7 cell lines was examined by western blot analysis. (A) Blots of ZIC1 and survivin expression in representative samples; (B) Relative protein expression of ZIC1 in 20 pairs of breast tumors was obviously lower than that in matched normal tissues, while expression of survivin in breast tumors was obviously higher than that in matched normal tissues; N, normal tissue; $\mathrm{T}$, breast tumor tissue, ${ }^{* * *} \mathrm{P}<0.001$; (C) Blots of ZIC1 and survivin expression in 6 breast cancer cell lines and MCF-10A normal mammary epithelial cells; (D) Relative protein expression of ZIC1 in 6 breast cancer cell lines was obviously lower than that in MCF-10A normal cells, while expression of survivin in breast cancer cell lines was obviously higher than that in MCF-10A normal cells, ${ }^{* * *} \mathrm{P}<0.001$. 
A

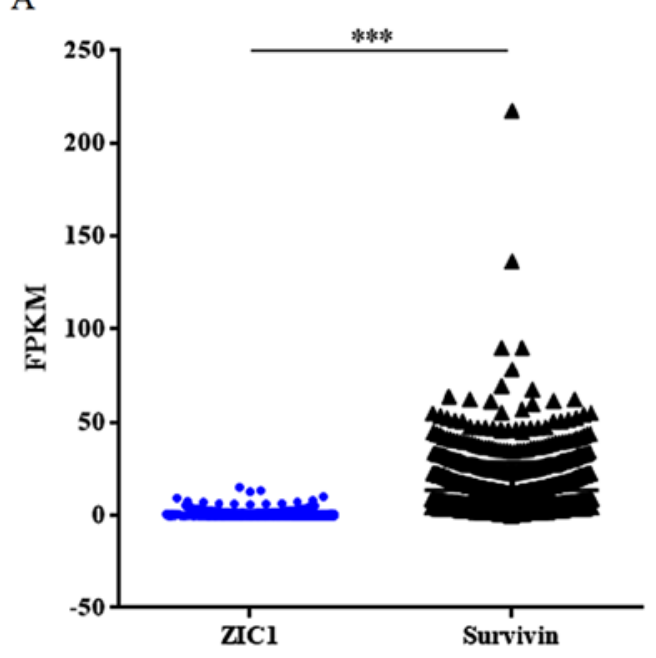

B ZIC1



Survivin

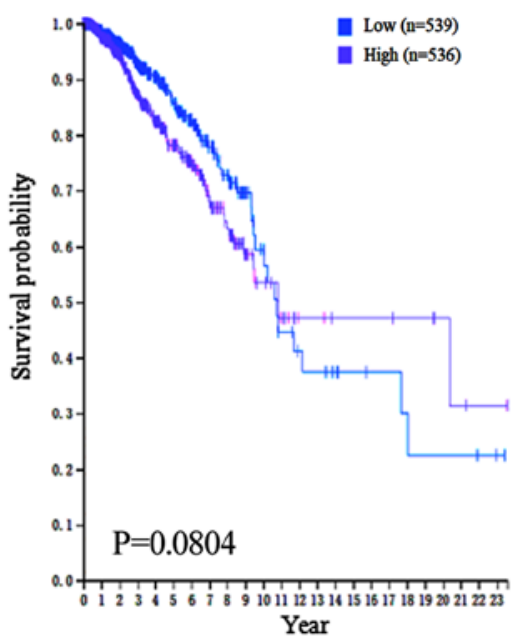

Figure 3. Analyses of ZIC1 and survivin in 1,075 TCGA RNA breast cancer samples. (A) ZIC1 fragments per kilobase million (FPKM) were obviously lower than survivin FPKM in 1,075 samples, ${ }^{* * *} \mathrm{P}<0.001$; (B) Left graph shows Kaplan-Meier curves for breast cancer according to ZIC1 expression. The prognosis of patients with a high ZIC1 expression ( $\mathrm{n}=799)$ was better than that of those with a low ZIC1 expression $(\mathrm{n}=276)(\mathrm{P}=0.013)$. Right graph shows Kaplan-Meier curves for breast cancer according to survivin expression. No significant difference was detected between the prognosis for patients with a high survivin expression $(\mathrm{n}=536)$ and those with a low survivin expression $(\mathrm{n}=539)(\mathrm{P}=0.080)$.

with tumor differentiation $(\mathrm{P}<0.001)$, lymph node metastasis $(\mathrm{P}=0.047)$ and TNM staging $(\mathrm{P}<0.001)$.

ZICl expression is inversely associated with surviving expression in breast cell and breast cancer cell lines. The relative expression levels of ZIC1 and survivin in 6 cancer cell lines and 1 normal breast cell line are presented in Fig. 2C and D. All the breast cancer cell lines that were examined (MCF-7, MDA-MB-231, MDA-MB-453, SK-BR3, BT-474 and BT-549) exhibited consistently lower levels of ZIC1 expression $(\mathrm{F}=31.30, \mathrm{P}<0.001)$ and higher levels of survivin expression $(\mathrm{F}=13.14, \mathrm{P}<0.001)$ than the MCF-10A normal breast epithelial cells. In addition, we found that the MDA-MB-231 and SK-BR3 cells exhibited lower expression levels of ZIC1 than the other breast cancer cells. Thus, these two cell lines were selected for transfection with lentivirus and for use in in vitro assays using the stably transfected cells.

Analysis of ZICl and survivin in the HPA. From the HPA, the RNA levels of ZIC1 and survivin of 1,075 TCGA RNA breast cancer samples were available. The average RNA level of ZIC1 was significantly lower than that of survivin $(0.64 \pm 1.44$ vs. $13.56 \pm 14.52, \mathrm{P}<0.0001$; Fig. $3 \mathrm{~A})$. In survival analyses, 0.0 fragments per kilobase million (FPKM) and 9.2 FPKM were used as the expression cut-off values for ZIC1 and survivin, respectively. As a result, 799 samples were included in the 'ZIC1 high' group, with a higher 5-year survival rate [high vs. low, 84 vs. $76 \%$ (671/799 vs. 210/276 from HPA database), $\mathrm{P}=0.0133$; Fig. 3B] while 536 samples were included in the 'survivin high' group, with a lower survival rate [high vs. low, 78 vs. $85 \%$ (418/536 vs. $458 / 539$ from HPA database), $\mathrm{P}=0.0804$; Fig. 3B].

ZICl inhibits the proliferation and promotes the apoptosis of breast cancer cells. Following transfection with rLV-ZsGreenPGK-Puro or rLV-Zic1-PGK-Puro and selection by puromycin, the stably transfected MDA-MB-231 and SK-BR3 cells were cultured conventionally. The distributions of green fluorescence in the two cell lines transfected with rLV-ZsGreen-PGK-Puro were both $>90 \%$, and in western blot analysis, the relative expression levels of ZIC1 in the 'ZICl' group were markedly higher than those in the 'Vector' group. Thus, we confirmed that high levels of ZIC1 expression were only observed in the 'ZICl' group, and not in the 'Vector' group (Fig. 4). In addition, the expression levels of survivin in the 'ZIC1' group were significantly decreased, in comparison with those in the 'Vector' group (Fig. 4), which indicated that an elevated ZIC1 expression may downregulate the expression level of survivin in breast cancer cells.

We then performed cell viability assay, colony formation assay and cell cycle analysis in the stably transfected cells to examine the effect of ZIC1 on cell proliferation in breast cancer. As shown in Fig. 5A, the enhanced expression of ZIC1 markedly suppressed the viability of the MDA-MB-231 and SK-BR3 cells $(\mathrm{P}<0.05)$. We also observed that the number of colonies formed on 6-well plates in the 'ZIC' group was markedly lower less than that in the 'Vector' group $(\mathrm{P}<0.01$; Fig. 5B). In addition, we obtained a higher proportion of MDA-MB-231 and SK-BR3 cells in the G1 phase following transfection with rLV-Zic1-PGK-Puro (Fig. 5C). These results confirmed the suppressive role of $\mathrm{ZIC1}$ on the proliferation of breast cancer cells.

After extracting mitochondrial proteins and obtaining the corresponding cytosol, we detected the relative expression levels of Cyto-c in the mitochondria and cytosol by western blot analysis. In the mitochondria, the expression level of Cyto-c was markedly lower in the 'ZICl' group than in the 'Vector' group, while in the cytosol, the level of Cyto-c was significantly enhanced in the ' $\mathrm{ZICl'}$ group in comparison with the 'Vector' group, which suggested that Cyto-c was released from the mitochondria into the cytosol following the overexpression of ZIC1 (Fig. 5D). In addition, the ratios of red 
A

MDA-MB-23
SK-BR3
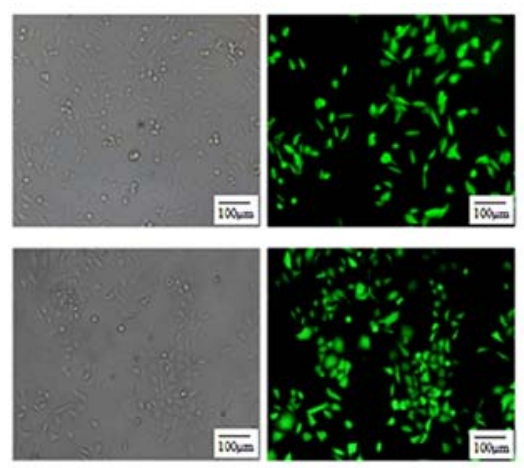

$\mathrm{C}$

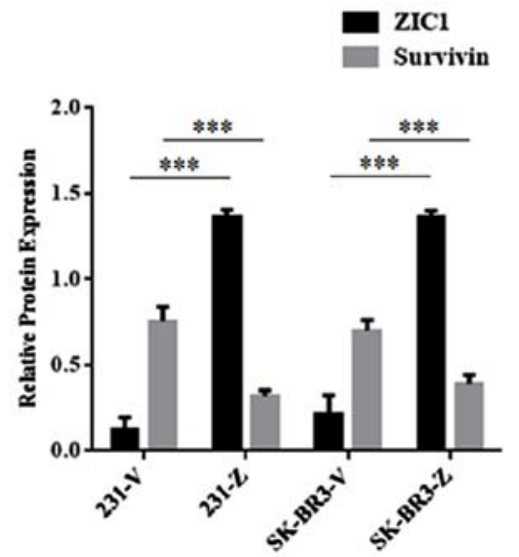

B

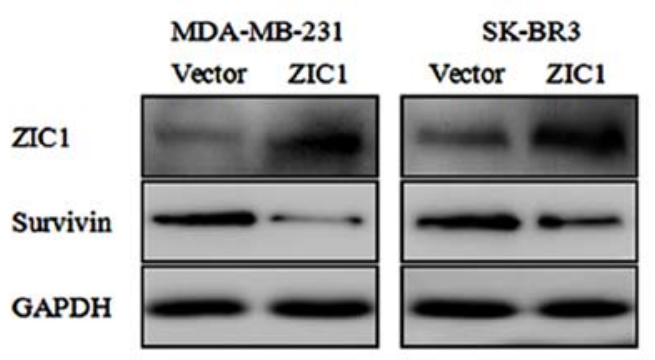

$\mathrm{D}$



Figure 4. Assessment of lentiviral transfection in breast cancer cells. (A) MDA-MB-231 (upper diagram) and SK-BR3 (low diagram) transfected with rLV-ZsGreen-PGK-Puro in a bright field microscope (left panels: magnification, x100) and green fluorescence microscope (right panels: magnification, x100). (B) Ectopic expression of ZIC1 and survivin in MDA-MB-231 and SK-BR3 cells was examined by western blot analysis. (C) Relative protein expression of ZIC1 in the 'ZICl' groups was obviously higher than that in the 'Vector' groups, while the expression of survivin in the 'ZICl' groups (Z) was obviously lower than that in the 'Vector' groups (V), ${ }^{* * *} \mathrm{P}<0.001$; (D) The $2^{-\Delta \Delta C q}$ value of ZIC1 in the 'ZICl' groups was markedly higher than that in the 'Vector' groups, while the $2^{-\Delta \Delta C q}$ value of survivin in the 'ZICl' groups was markedly lower than that in the 'Vector' groups, ${ }^{* * * *} \mathrm{P}<0.001$.

to green fluorescence were markedly decreased in the ' $\mathrm{ZIC1}$ ' group (Fig. 5E). The rates of cell apoptosis were also markedly increased in the cells transfected with the ZIC1 overexpression vector (Fig. 5F). These results suggested that an elevated ZIC1 expression reduces the mitochondrial membrane potential of breast cancer cells and induces apoptosis.

ZIC1 suppresses tumor growth in vivo. We subcutaneously transplanted rLV-ZsGreen-PGK-Puro- or rLV-Zic1-PGK-Purotransfected MDA-MB-231 cells into nude mice. Each mouse had only one transplanted tumor. After 39 days of transplantation, the tumors of the mice in the ' $\mathrm{ZICl}$ ' group were consistently smaller than those of the mice in the 'Vector' group (the maximum tumor diameter in the 'ZICl' group was $1.26 \mathrm{~cm}$, while the maximum tumor diameter in the 'Vector' group was $1.60 \mathrm{~cm}$; Fig. 6A). In addition, the sizes of the tumors during the period of 39 days were markedly lower in the 'ZIC1' group, in comparison with the 'Vector' group (Fig. 6B). We also validated that high levels of ZIC1 expression and low levels of survivin expression were both observed in the 'ZICl' group. Opposite results were observed in the 'Vector' group (Fig. 6C).

ZIC1 inhibits survivin expression by inactivating the Akt/mTOR/P70S6K signaling pathway. To explore potential mechanisms underlying the suppressive role of ZIC1 in breast cancer and its regulatory effect on survivin expression, we investigated critical proteins of the Akt signaling pathway, which play a pivotal role in cell proliferation and survival in breast cancer $(19,20)$. As shown in Fig. 7A, the overexpression of ZIC1 significantly reduced phosphorylation levels of Akt, mTOR and P70S6K, and suppressed the activities of this pathway both in the MDA-MB-231 and SK-BR3 breast cancer cells. In addition, the ectopic expression of ZIC1 downregulated cyclin D1 and upregulated p21 and p27 expression, which indicated that ZIC1 arrested the breast cancer cells at the G1 phase via modulating the expression levels of these proteins. Our data also indicated that the upregulation of ZIC1 led to the decreased expression of Bcl-2 and Bcl-xL, the dephosphorylation of Bad and the activation of cleaved caspase- 9 and cleaved caspase-3 (Fig. 7A). These results suggested that ZIC1 reduces mitochondrial membrane potential and promotes the apoptosis of breast cancer cells through the mitochondrial apoptotic pathway. Combined with the molecular modulatory mechanisms of survivin found in previous studies (17,21-23), a schematic model of the potential mechanisms of ZIC1 protein is presented in Fig. 7B.

\section{Discussion}

Due to changes in the environment and in spite of advances in detection techniques, breast cancer has become a leading threat to the lives of women worldwide. Numerous oncogenes and anti-oncogenes in breast carcinogenesis are constantly 

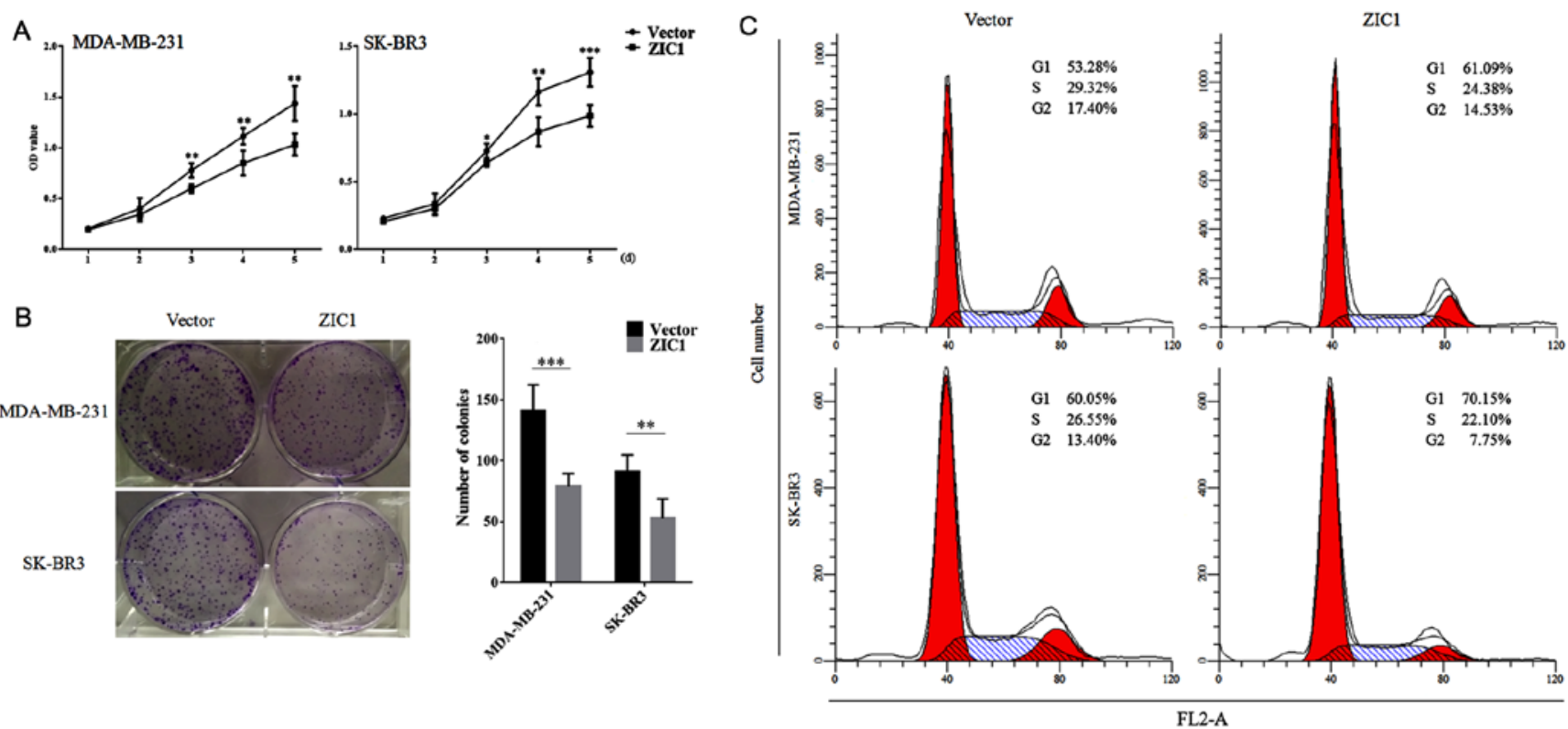

D
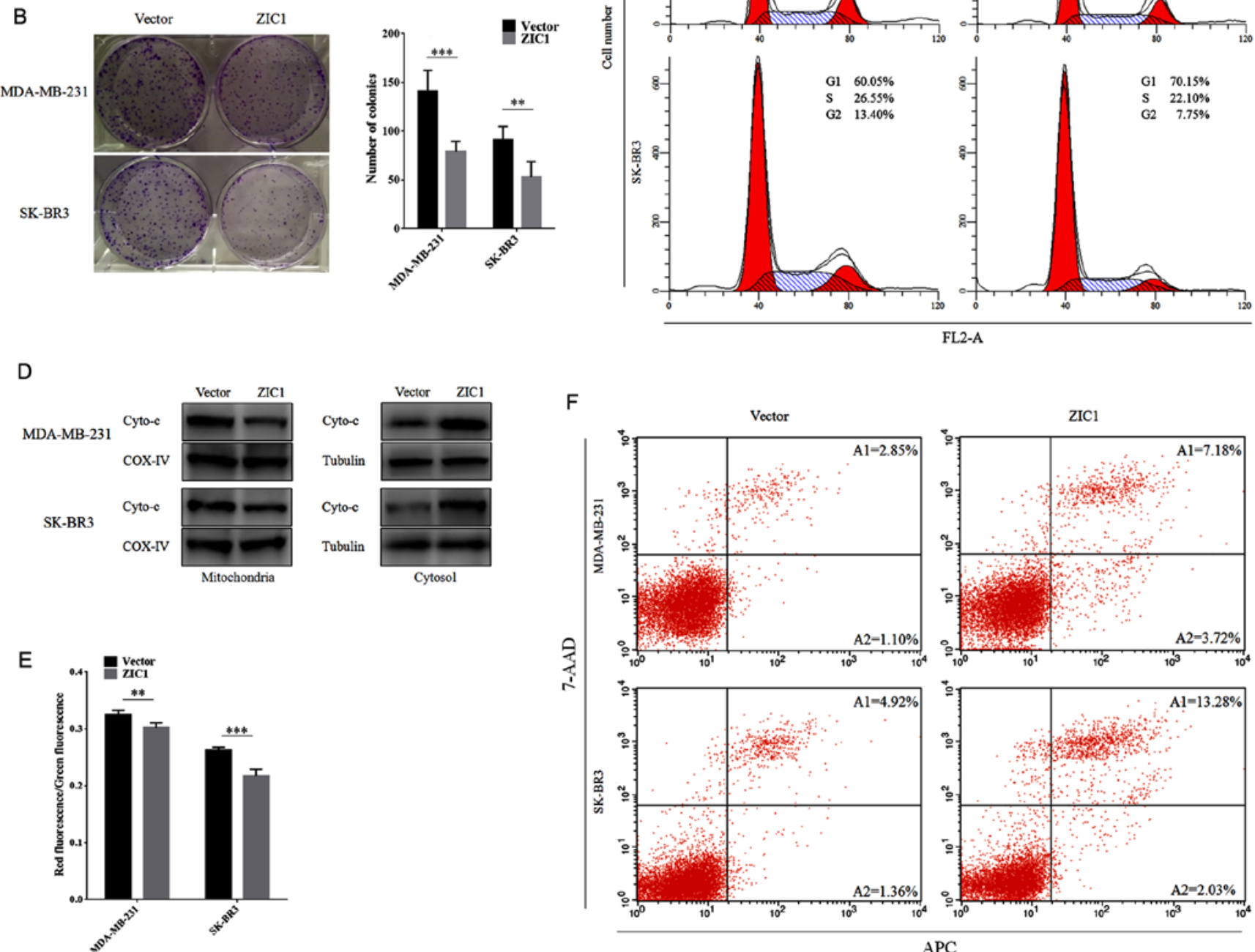

$\therefore$
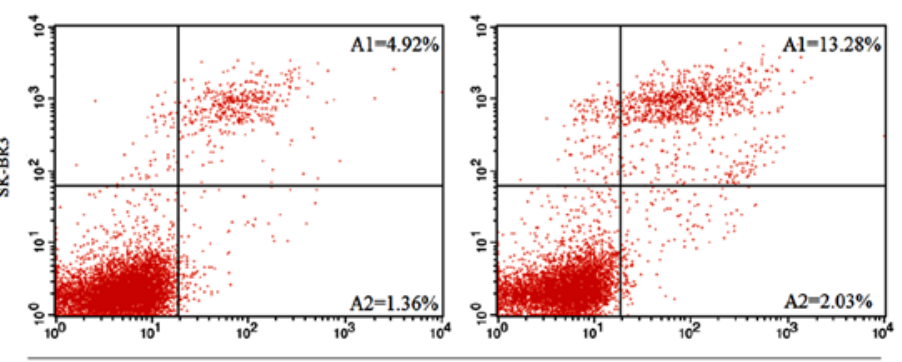

Figure 5. ZIC1 suppresses cell proliferation, reduces mitochondrial membrane potential and promotes apoptosis in breast cancer. (A) The viability of stably transfected breast cancer cells was determined by MTT cell proliferation assay; ${ }^{*} \mathrm{P}<0.05,{ }^{* *} \mathrm{P}<0.01$ and ${ }^{* * * *} \mathrm{P}<0.001$. (B) The effects of ZIC1 on cell growth were confirmed by colony formation assay (left diagrams show representative images and the right graph shows the quantitative analysis of colony numbers), ${ }^{* *} \mathrm{P}<0.01$ and ${ }^{* * *} \mathrm{P}<0.001$. (C) Cell cycle distributions were detected by flow cytometric analysis in stably transfected breast cancer cells. (D) Blots of Cyto-c expression in mitochondria and cytosol of stably transfected cells. (E) Relative protein expression of Cyto-c expression in mitochondria and cytosol of stably transfected cells, ${ }^{* *} \mathrm{P}<0.01$ and ${ }^{* * * *} \mathrm{P}<0.001$. (F) Cell apoptotic rates were detected by flow cytometry in stably transfected breast cancer cells.

identified. ZIC1 is a zinc finger transcription factor involved in neural development and serves as a tumor suppressor gene in solid tumors (6-8). In this study, we first found that ZIC1 expression in breast tumors was significantly lower than that in normal tissues, both through immunohistochemistry and western blot analysis, and ZIC1 expression was negatively associated with tumor differentiation and TNM staging. In addition, the expression levels of ZIC1 in 6 breast cancer cell lines were also lower than those in the MCF-10A cells, a normal breast cell line. These results suggest that ZIC1 may be a potential tumor suppressor in breast cancer. Furthermore, a low ZIC1 expression predicted a poor prognosis from the HPA.
To verify the tumor suppressive role of ZIC1 in breast cancer cells, we transfected rLV-ZsGreen-PGK-Puro or rLV-Zic1-PGK-Puro into two breast cell lines, MDA-MB-231 and SK-BR3, in which the expression levels of ZIC1 were lower than in the other cell lines. In vitro, the stably transfected cells overexpressing ZIC1 had lower cell proliferative abilities and elevated apoptotic rates. In addition, compared with the 'Vector' group, a markedly smaller tumor growth was observed the 'ZIC1' group, following the transplantation of stably transfected MDA-MB-231 cells into nude mice. All the results revealed that $\mathrm{ZIC1}$ may function as a tumor suppressor in breast carcinogenesis; however, this should be confirmed in further studies. As reported in a previous study, ZIC1 is a 
A

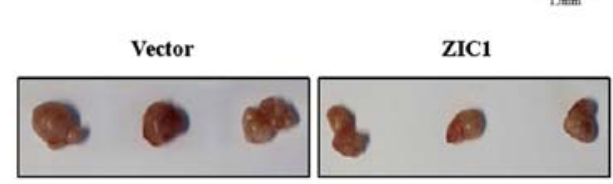

C

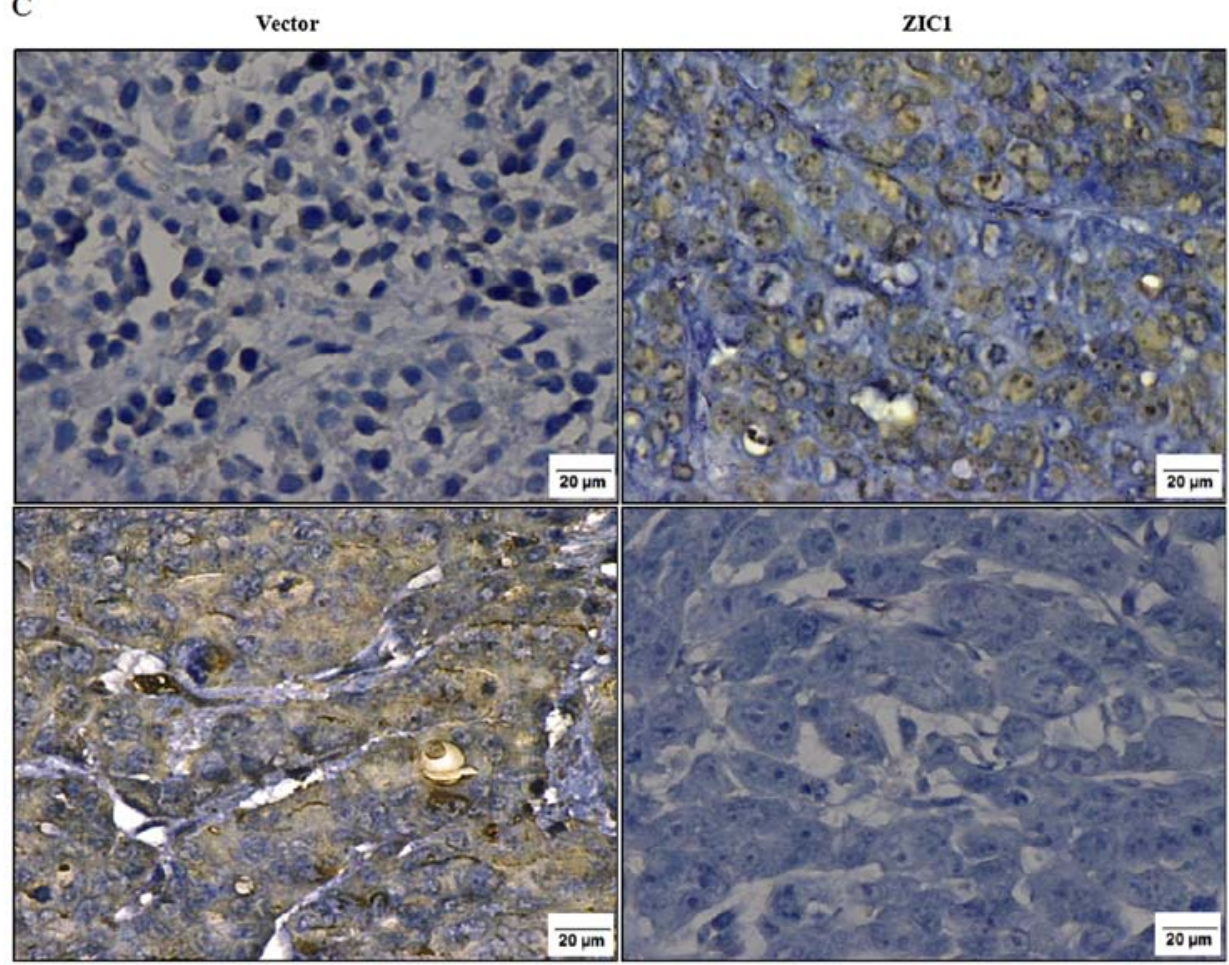

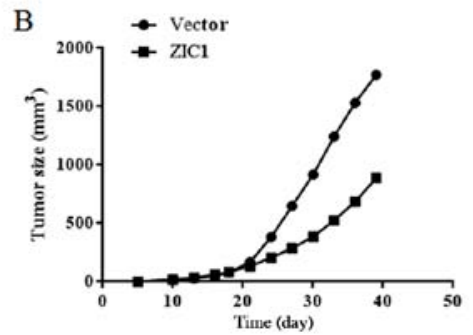

ZIC1 expression

Survivin expression $\mu \mathrm{m}$

Figure 6. ZIC1 inhibits tumor formation in vivo. (A) Empty vector and ZIC1 transfectant tumors; (B) growth curves of empty vector and ZIC1 transfectant tumors; (C) expression of ZIC1 and survivin in empty vector and ZIC1 transfectant tumors was examined by immunohistochemistry (magnification, $\mathrm{x} 400$ ).

A

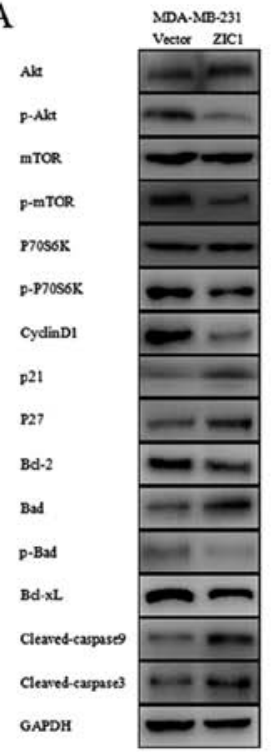

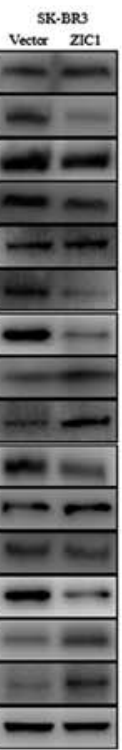

B

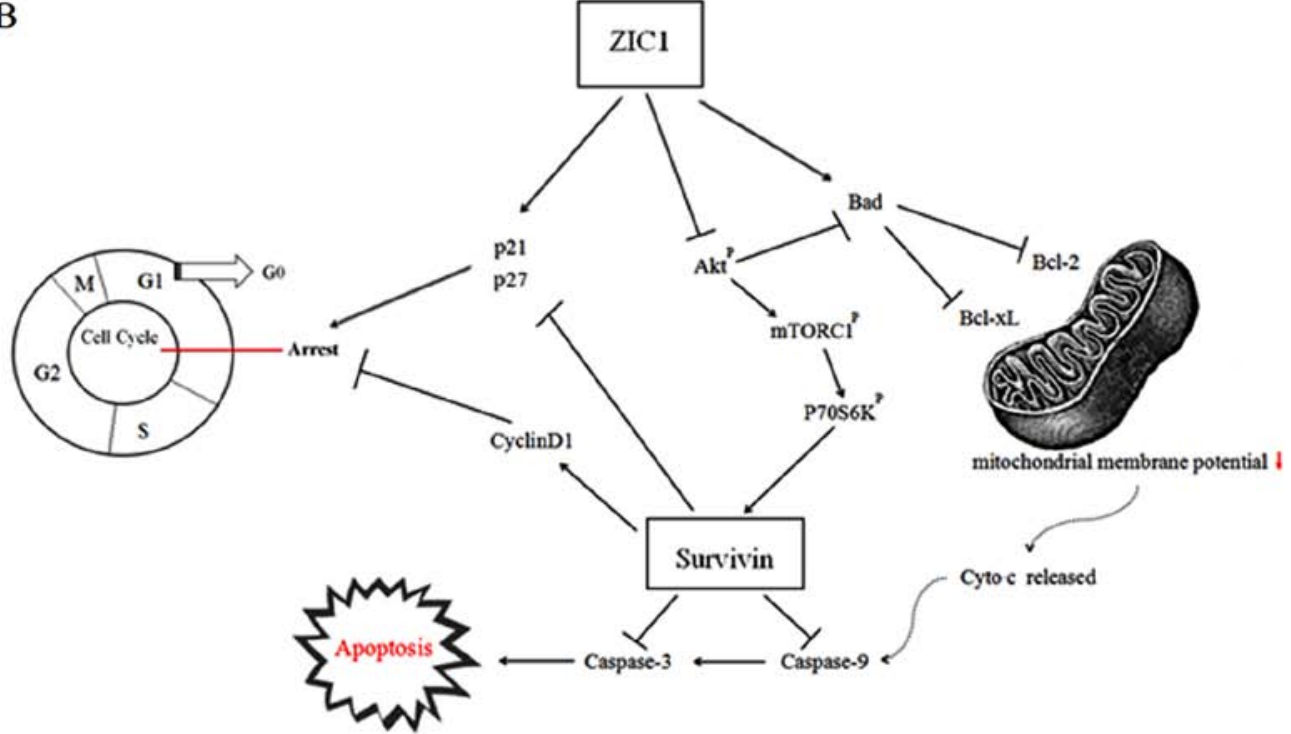

Figure 7. The moleculular mechanisms of action of ZIC1 in breast cancer. (A) Proteins of the Akt/mTOR/P70S6K pathway, cell cycle regulatory proteins and apoptosis-related proteins in MDA-MB-231 and SK-BR3 breast cancer cells with or without ectopic expression of ZIC1 were investigated by western blot analysis. (B) Schematic model of the role of ZIC1 in breast cancer: ZIC1 inhibits survivin expression by the blockade of the Akt/mTOR/P70S6K signaling pathway; the reduced expression of survivin and the ectopic expression of ZIC1 induce cell cycle arrest at the G1 phase together; ZIC1 releases Cyto-c from the mitochondria and then promotes the apoptosis of breast cancer cells; and reduced expression of survivin diminished the suppression of cleaved caspase- 9 and cleaved caspase-3. 
putative tumor suppressor gene and is upregulated in breast cancer cells when phosphatidylinositol glycan anchor biosynthesis, class X containing complex (PIGX) inhibits the growth of transfected BT-549 cells (11). To the best of our knowledge, this study was the first to identify the tumor suppressive function of ZIC1 by using stable transfection technology in breast cancer.

In the mechanistic analysis, the expression levels of p-Akt, p-mTOR, p-P70S6K, Cyclin D1, Bcl-2 and Bcl-xL were markedly decreased in the 'ZIC1' group, while the expression levels of p21, p27, Bad, cleaved caspase-9 and cleaved caspase-3 were significantly increased. In addition, this study identified that the mitochondrial membrane potential of the breast cancer cells, transfected with rLV-Zic1-PGK-Puro, was markedly decreased, due to the dysregulated expression of $\mathrm{Bcl}-2$ family proteins. In addition, Cyto-c in the mitochondria was released into the cytosol, which regulated the activation of caspase-9 and caspase-3. Thus, we confirmed that ZIC1 was a potential inhibitor of the Akt/mTOR/P70S6K pathway, and a promoter of the activation of the mitochondrial apoptotic pathway. Previous studies have also demonstrated that ZIC1 is a regulator of the PI3K/Akt pathway, and can lead to decreased phosphorylation levels of Akt (6-8). However, these studies only found the regulatory effect of ZIC1 on the expression of Bcl-2, Bax and Bad. None of these analyzed the changes in the levels of mitochondrial membrane potential in cancer cells. The findings of this study indicated that ZIC1 overexpression markedly suppressed tumor growth by modulating these pathways.

As a member of the family of the inhibitors of apoptosis proteins (IAPs), survivin forcefully inhibits cell apoptosis and facilitates the activation and proliferation of breast cancer cells (24). Admittedly, survivin is a downstream target of $\mathrm{NF}-\kappa \mathrm{B}$, which in turn is activated by mTOR (25). Furthermore, survivin is a potent inactivator of caspase- 9 and caspase- 3 and is regulated via the Akt/mTOR signaling pathway $(16,17)$. In this study, in 120 female patients with breast cancer, compared with $\mathrm{ZIC1}$, the expression level of survivin in the tumors was markedly higher, and a negative correlation was observed between $\mathrm{ZIC1}$ and surviving expression. In addition, the role of survivin in the clinicopathological characteristics was opposite to that of ZIC1. Both in breast cancer cell lines and the breast cell line, the expression level of survivin was inversely associated with that of ZIC1. In addition, following transfection with rLV-Zic1-PGK-Puro, survivin expression was markedly decreased in the stably transfected cells, as well as in xenograft tumors. Therefore, we demonstrated that an elevated ZIC1 expression suppressed the expression of survivin through the Akt/mTOR/P70S6K pathway, and then activate caspase- 9 and caspase-3, so as to induce the apoptosis of breast cancer cells.

The promoter of survivin contains 3 cell cycledependent element (CDE) and a cell-cycle gene homology region (CHR), which induce survivin expression intensively at the $\mathrm{G} 2 / \mathrm{M}$ phase, and determine its significance in cell cycle control (26). The silencing the expression of survivin through RNAi has been shown to affect the expression levels of Cyclin D1, p21 and p27, so that the cell cycle is arrested at the G1 phase, which eventually induces the apoptosis of hepatocellular carcinoma cells (27). In this study, the overexpression of
ZIC1 suppressed the expression of survivin via the inactivation of the Akt/mTOR/P70S6K pathway. Consequently, decreased survivin expression induced the expression of p21 and p27, and led to the downregulation of Cyclin D1. Therefore, it can be hypothesized that ZIC1 overexpression induces a $\mathrm{G} 1$ phase block directly via modulating cell cycle related proteins, or indirectly by reducing survivin expression.

Although Brill et al (28) revealed that ZIC1 contributed to the pathogenesis of liposarcoma, recent evidence suggested that ZIC1 was downregulated due to hypermethylation in its promoter region in a variety of carcinomas, including gastric cancer, thyroid cancer, ovarian cancer and cervical cancer (6,29-31). In cervical cancer, ZIC1 may become a promising methylation marker, which is associated with a $3 q$ gain for the detection of cervical pre-cancer and cervical carcinoma (30). In ovarian cancer, the hypermethylation of $\mathrm{ZIC1}$ is associated with cisplatin resistance and it may serve as a potential therapeutic target $(31,32)$. Therefore, the methylation of the $\mathrm{ZIC1}$ promoter causes its low expression in malignant cells, and is a key reason for carcinogenesis. In addition, a lower expression of ZIC1 in gastric carcinoma has been confirmed to be associated with a worse prognosis (10). Based on its molecular mechanisms of action, the DNA methylation of ZIC1 has been used for clinicopathological diagnosis, targeted clinical treatment, and prognostic evaluation in various solid neoplasms (7).

In this study, we explored the main functions of ZIC1 in cell proliferation and apoptosis and relevant downstream genes, which suggested that ZIC1 may be a potential tumor suppressor gene. However, the upstream regulatory mechanisms of ZIC1 in inhibiting the growth of cancer cells or targeted drugs are still at a preliminary stage. Following the transfection of BT-549 cells with siRNAs targeting the PIGX containing complex, Nakakido et al found a strong suppression of the growth of breast cancer cells in vitro, along with a significant upregulation of ZIC1 expression through cDNA microarray analysis (11). In addition, SGI-110, a dinucleotide combining 5-aza-dC and deoxyguanosine, was found to cause the powerful hypomethylation of ZIC1 in female nude, athymic, BALB/c-nu/nu mice through pyrosequencing analyses (32). The biweekly treatment regimen of SGI-110 also markedly decreased xenograft tumor growth (32).

In this study, the MDA-MB-231 cell line was a triplenegative breast cancer, while the SK-BR-3 cell line was a human epidermal growth factor receptor 2 (HER2) overexpressing cell line. We selected 6 different breast cancer cell lines and found that the MDA-MB-231 and SK-BR3 expressed lower levels of $\mathrm{ZIC1}$ than the other cell lines. We used these two cell lines in order to assess the role of ZIC1 more clearly. In addition, due to totally different genomic background of these two cell lines, we demonstrated that ZIC1 acted a tumor suppressor in breast cancer without the influence of HER2 expression. However, the overexpression had its limitation as it was not a physiological event and further mechanistic effect remained to be proven. Due to insufficient follow-ups, we did not evaluate the prognostic role of $\mathrm{ZIC1}$. However, from the HPA, 799 samples were included in the 'ZIC1 high' group, with a higher 5-year survival rate than the 'ZIC1 low' group. Thus, we aim to conduct overall survival analysis with larger samples in the future. 
In conclusion, we confirmed that the expression level of ZIC1 was decreased in breast cancer samples, as well as in breast cancer cell lines, and an elevated ZIC1 expression suppressed the growth of breast cancer cells and xenograft tumors, along with a significant downregulation in surviving expression via the Akt/mTOR/P70S6K pathway. Although further investigations are required, our findings illustrate the tumor suppressive role of ZIC1 in breast carcinoma and a negative association between $\mathrm{ZIC1}$ and survivin.

\section{Acknowledgements}

Not applicable.

\section{Funding}

This study was funded by the following: i) The Kunshan Science and Technology Program of Social Development (no. KS1730); ii) the Jiangsu General University Program of Practical Innovation of Professional Postgraduate Degree (no. SJLX16_0450); and iii) the Jiangsu University Science and Technology Program of Clinical Medicine (no. JLY20120050).

\section{Availability of data and materials}

All data generated or analyzed during this study are included in this published article.

\section{Authors' contributions}

WH, HZD, FCa and HBW conceived and designed the study. WH, FCa and HBW drafted the manuscript. WH, XJG, FCa and $\mathrm{HBW}$ participated in implementation of the study. $\mathrm{CZ}$, $\mathrm{FCh}, \mathrm{YWH}, \mathrm{JM}$ and $\mathrm{XG}$ assisted in collecting the data. WH, FCa and SJC performed the statistical analysis. All authors read and approved the final manuscript.

\section{Ethics approval and consent to participate}

The use of patient samples was approved by Kunshan First People's Hospital Ethics Committee. Each patient signed the informed consent form. All animal research was carried out following the approval of the Jiangsu University Animal Ethics Committee (Jiangsu, China).

\section{Patient consent for publication}

Not applicable.

\section{Competing interests}

The authors declare that they have no competing interests.

\section{References}

1. Siegel RL, Miller KD and Jemal A: Cancer statistics, 2015. CA Cancer J Clin 65: 5-29, 2015.

2. Ding L, Zhang Z, Xu Y and Zhang Y: Comparative study of Her-2, p53, Ki-67 expression and clinicopathological characteristics of breast cancer in a cohort of northern China female patients. Bioengineered 8: 383-392, 2017.
3. Parsa Y, Mirmalek SA, Kani FE, Aidun A, Salimi-Tabatabaee SA, Yadollah-Damavandi S, Jangholi E, Parsa T and Shahverdi E: A review of the clinical implications of breast cancer biology. Electron Physician 8: 2416-2424, 2016.

4. Ali RG, Bellchambers HM and Arkell RM: Zinc fingers of the cerebellum (Zic): Transcription factors and co-factors. Int $\mathrm{J}$ Biochem Cell Biol 44: 2065-2068, 2012.

5. Sankar S, Yellajoshyula D, Zhang B, Teets B, Rockweiler N and Kroll KL: Gene regulatory networks in neural cell fate acquisition from genome-wide chromatin association of Geminin and Zic1. Sci Rep 6: 37412, 2016.

6. Zhong J, Chen S, Xue M, Du Q, Cai J, Jin H, Si J and Wang L: ZIC1 modulates cell-cycle distributions and cell migration through regulation of sonic hedgehog, PI(3)K and MAPK signaling pathways in gastric cancer. BMC Cancer 12: 290, 2012

7. Gan L, Chen S, Zhong J, Wang X, Lam EK, Liu X, Zhang J, Zhou T, Yu J, Si J, et al: ZIC1 is downregulated through promoter hypermethylation, and functions as a tumor suppressor gene in colorectal cancer. PLoS One 6: e16916, 2011.

8. Qiang W, Zhao Y, Yang Q, Liu W, Guan H, Lv S, Ji M, Shi B and Hou P: ZIC1 is a putative tumor suppressor in thyroid cancer by modulating major signaling pathways and transcription factor FOXO3a. J Clin Endocrinol Metab 99: E1163-E1172, 2014.

9. Wang YY, Jiang JX, Ma H, Han J, Sun ZY, Liu ZM and Xu ZG: Role of ZIC1 methylation in hepatocellular carcinoma and its clinical significance. Tumour Biol 35: 7429-7433, 2014.

10. Ma G, Dai W, Sang A, Yang X and Li Q: Roles of ZIC family genes in human gastric cancer. Int J Mol Med 38: 259-266, 2016.

11. Nakakido M, Tamura K, Chung S, Ueda K, Fujii R, Kiyotani K and Nakamura Y: Phosphatidylinositol glycan anchor biosynthesis, class $\mathrm{X}$ containing complex promotes cancer cell proliferation through suppression of EHD2 and ZIC1, putative tumor suppressors. Int J Oncol 49: 868-876, 2016.

12. Tamm I, Wang Y, Sausville E, Scudiero DA, Vigna N, Oltersdorf $\mathrm{T}$ and Reed JC: IAP-family protein survivin inhibits caspase activity and apoptosis induced by Fas (CD95), Bax, caspases, and anticancer drugs. Cancer Res 58: 5315-5320, 1998.

13. Colnaghi R, Connell CM, Barrett RM and Wheatley SP: Separating the anti-apoptotic and mitotic roles of survivin. J Biol Chem 281: 33450-33456, 2006.

14. Hamy AS, Bieche I, Lehmann-Che J, Scott V, Bertheau P, Guinebretière JM, Matthieu MC, Sigal-Zafrani B, Tembo O, Marty M, et al: BIRC5 (survivin): A pejorative prognostic marker in stage II/III breast cancer with no response to neoadjuvant chemotherapy. Breast Cancer Res Treat 159: 499-511, 2016.

15. Véquaud E, Desplanques G, Jézéquel P, Juin P and Barillé-Nion S: Survivin contributes to DNA repair by homologous recombination in breast cancer cells. Breast Cancer Res Treat 155: 53-63, 2016.

16. Wilson JM, Kunnimalaiyaan S, Kunnimalaiyaan M and Gamblin TC: Inhibition of the AKT pathway in cholangiocarcinoma by MK2206 reduces cellular viability via induction of apoptosis. Cancer Cell Int 15: 13, 2015.

17. Jin Q, Feng L, Behrens C, Bekele BN, Wistuba II, Hong WK and Lee HY: Implication of AMP-activated protein kinase and Akt-regulated survivin in lung cancer chemopreventive activities of deguelin. Cancer Res 67: 11630-11639, 2007.

18. Livak KJ and Schmittgen TD: Analysis of relative gene expression data using real-time quantitative PCR and the 2(-Delta Delta C(T)) method. Methods 25: 402-408, 2001.

19. Li Q, Liu J, Meng X, Pang R and Li J: MicroRNA-454 may function as an oncogene via targeting AKT in triple negative breast cancer. J Biol Res (Thessalon) 24: 10, 2017.

20. Sauer SJ, Tarpley M, Shah I, Save AV, Lyerly HK, Patierno SR, Williams KP and Devi GR: Bisphenol A activates EGFR and ERK promoting proliferation, tumor spheroid formation and resistance to EGFR pathway inhibition in estrogen receptornegative inflammatory breast cancer cells. Carcinogenesis 38 : 252-260, 2017.

21. Du G, Cao D and Meng L: miR-21 inhibitor suppresses cell proliferation and colony formation through regulating the PTEN/ AKT pathway and improves paclitaxel sensitivity in cervical cancer cells. Mol Med Rep 15: 2713-2719, 2017.

22. Ding JH, Yuan LY and Chen GA: Aspirin enhances the cytotoxic activity of bortezomib against myeloma cells via suppression of Bcl-2, survivin and phosphorylation of AKT. Oncol Lett 13: 647-654, 2017.

23. Wu ZH, Lin C, Liu MM, Zhang J, Tao ZH and Hu XC: Src inhibition can synergize with gemcitabine and reverse resistance in triple negative breast cancer cells via the AKT/c-Jun pathway. PLoS One 11: e0169230, 2016. 
24. Khan Z, Khan AA, Yadav H, Prasad GBKS and Bisen PS Survivin, a molecular target for therapeutic interventions in squamous cell carcinoma. Cell Mol Biol Lett 22: 8, 2017.

25. Kawakami H, Tomita M, Matsuda T, Ohta T, Tanaka Y, Fujii M, Hatano M, Tokuhisa T and Mori N: Transcriptional activation of survivin through the NF-kappaB pathway by human T-cell leukemia virus type I tax. Int J Cancer 115: 967-974, 2005.

26. Lens SM, Vader G and Medema RH: The case for survivin as mitotic regulator. Curr Opin Cell Biol 18: 616-622, 2006.

27. Liu W, Zhu F, Jiang Y, Sun D, Yang B and Yan H: siRNA targeting survivin inhibits the growth and enhances the chemosensitivity of hepatocellular carcinoma cells. Oncol Rep 29: 1183-1188, 2013.

28. Brill E, Gobble R, Angeles C, Lagos-Quintana M, Crago A, Laxa B, Decarolis P, Zhang L, Antonescu C, Socci ND, et al: ZIC1 overexpression is oncogenic in liposarcoma. Cancer Res 70: 6891-6901, 2010.

29. Rodríguez-Rodero S, Fernández AF, Fernández-Morera JL, Castro-Santos P, Bayon GF, Ferrero C, Urdinguio RG, GonzalezMarquez R, Suarez C, Fernández-Vega I, et al: DNA methylation signatures identify biologically distinct thyroid cancer subtypes. J Clin Endocrinol Metab 98: 2811-2821, 2013.
30. Verlaat W, Snijders PJ, Novianti PW, Wilting SM, De Strooper LM, Trooskens G, Vandersmissen J, Van Criekinge W, Wisman GB, Meijer CJ, et al: Genome-wide DNA methylation profiling reveals methylation markers associated with $3 \mathrm{q}$ gain for detection of cervical pre-cancer and cancer. Clin Cancer Res 23: 3813-3822, 2017.

31. Du L, Qian X, Dai C, Wang L, Huang D, Wang S and Shen X: Screening the molecular targets of ovarian cancer based on bioinformatics analysis. Tumori 101: 384-389, 2015.

32. Fang F, Munck J, Tang J, Taverna P, Wang Y, Miller DF, Pilrose J, Choy G, Azab M, Pawelczak KS, et al: The novel, small-molecule DNA methylation inhibitor SGI-110 as an ovarian cancer chemosensitizer. Clin Cancer Res 20: 6504-6516, 2014.

This work is licensed under a Creative Commons Attribution-NonCommercial-NoDerivatives 4.0 International (CC BY-NC-ND 4.0) License. 